\title{
Hybrid Surfactant Systems with Inorganic Constituents
}

\author{
Sebastian Polarz,* Steve Landsmann, and Alexander Klaiber
}

\begin{abstract}
$\boldsymbol{S}_{\text {urfactants are molecules of enormous scientific and technological }}$ importance, which are widely used as detergents, emulsifiers, and for the preparation of diverse nanostructures. Their fascinating ability to form self-organized structures, such as micelles or liquid crystals, originate from their amphiphilic architecture-a polar head group linked to a hydrophobic chain. While almost all known surfactants are organic, a new family of surfactants is now emerging, which combines amphiphilic properties with the advanced functionality of transitionmetal building blocks, for example, redox or catalytic activity and magnetism. These hybrid surfactants exhibit novel self-organization features because of the unique size and electronic properties of the metal-containing entities.
\end{abstract}

\section{Introduction}

Surfactants (SURFs) represent a subclass of utmost interest among so called amphiphilic species. They are characterized by a special molecular architecture with dipolar character. Two parts with significantly different solvent compatibilities are joined together in one compound. The simplest SURFs contain one hydrophilic head group attached to one hydrophobic alkyl tail. This unique feature is responsible for their well known properties of self organiza tion and numerous applications. ${ }^{[1]}$ SURFs are broadly applied on a multiton scale as detergents, in cosmetics, as emulsifi cation agents, and as phase transfer catalysts. ${ }^{[2]}$ The develop ment of nanoscience would not have been possible without SURFs because of their ability to stabilize phases with a high surface to volume ratio such as nanoparticles or nanoporous materials. $^{[3]}$

The self organization behavior of SURFs is concentration dependent (Figure 1) and has been studied extensively in water: Initially, single surfactant molecules occupy the water/ air interface until it becomes densely packed. The formation of supramolecular structures takes place at higher concen trations and micellization can be observed. The hydrophilic head groups are localized at the micelle/water interface and the hydrophobic tails point inwards.

[*] Prof. Dr. S. Polarz, Dr. S. Landsmann, A. Klaiber Department of Chemistry, University of Konstanz 78457 Konstanz (Germany)

E mail: sebastian.polarz@uni konstanz.de

Homepage: http://cms.uni konstanz.de/polarz/

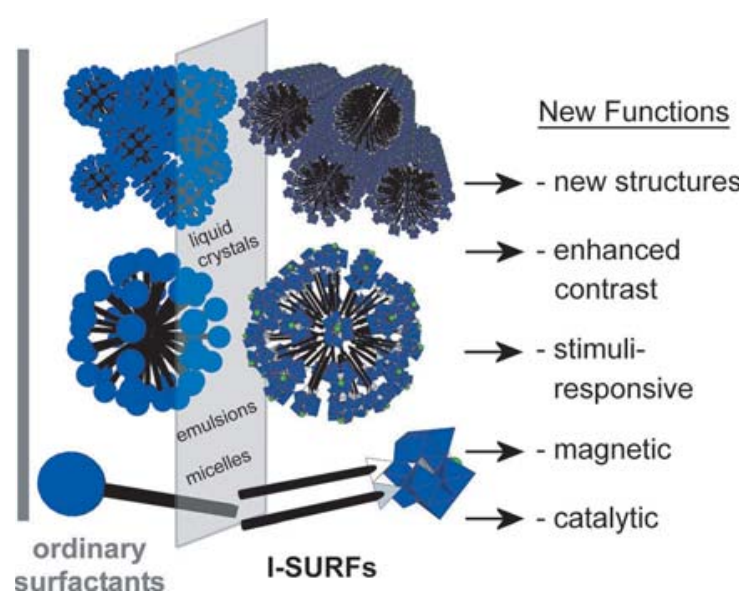

Figure 1. Similarities and differences between inorganic surfactants (I SURFs) and conventional, purely organic surfactants.

Some still valid theories about micellization were intro duced by Israelachvili more than 40 years ago. ${ }^{[4]}$ The type of aggregate observed at medium concentrations is influenced by the packing parameter, a characteristic number related to the shape of one single surfactant molecule. For example, surfactants with large heads and short tails have small packing parameters $(<1 / 3)$ and look like a cone. Thus, these surfactants tend to form structures characterized by high curvature, such as spherical micelles. At even higher concen trations one can induce the formation of mesophases and lyotropic liquid crystals (LLCs). A large variety of more or 
less complex LLC phases are now known, depending on the complexity of the surfactant architecture. ${ }^{[4]}$

Practically all the surfactants used in technological applications are organic in nature with head groups such as ammonium (cationic), oligoethylene glycol (neutral), or carboxylate (anionic). It is highly attractive to equip surfac tants with an enhanced set of properties, such as those characteristic of transition metal ions (e.g. different redox states, magnetic momentum, catalytic activity; Figure 1). Consequently, surfactants with inorganic constituents (I SURFs) can be considered to belong to the larger class of metallomesogens. ${ }^{[5]}$ The term metallomesogens was first introduced by Bruce and co workers for molecular species having the ability to form liquid crystalline (LC) phases and with coordination complexes as building blocks. ${ }^{[6]}$ Most of these early studies concentrated on systems with thermo tropic LC characteristics, for example, rodlike or platelike metal compounds. ${ }^{[7]}$ Some metal containing polymers and even inorganic particles forming LC phases or some supra crystals have since also be shown to belong to metallomes ogens. ${ }^{[8]}$ It should also be noted that metal directed self organization phenomena play a significant role in contempo rary fields such as coordination polymers and metal organic framework materials ${ }^{[9]}$ conjugated metallopolymers, ${ }^{[10]}$ and metallodendrimers. ${ }^{[11]}$

This Minireview will focus on highlighting some of the most important results and recent developments regarding surfactant systems with inorganic constituents, on molecular systems characterized by pronounced dipolar character, and which show self organization phenomena in the presence of solvents (lyotropic behavior). There are currently two ap proaches to generate a surfactant system with (transition) metal functionality (Scheme 1). The simplest method will be described in Section 2. It involves the use of conventional surfactants with metal containing species as counterions (type I). However, it is much more demanding and much more desirable if the metal building block is an integral part of the surfactant (type II), which will be discussed in Section 3.

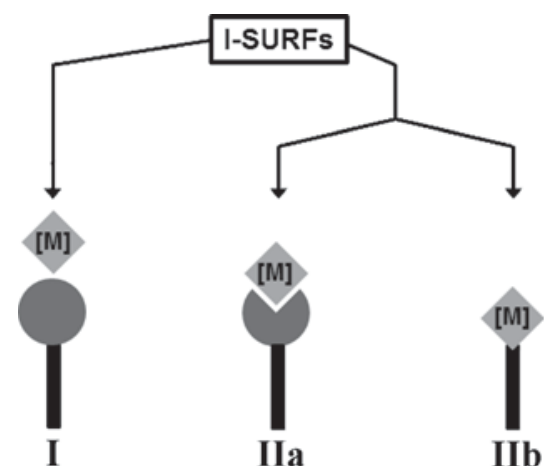

Scheme 1. Classification of different types of surfactants with inorganic constituents [M]. I) Electrostatic interaction between the surfactant and [M]; Ila) coordinative interaction between the head group and [M]; IIb) covalent attachment/[M] as a head group.

\section{Surfactants with Metal Compounds as Counterions (type I)}

It is clear that anionic surfactants with metal cations as counterions represent the simplest imaginable I SURF sys tem. ${ }^{[12]}$ The first examples of I SURFs (type I) were presented by Mirnaya et al. back in 1989, when the formation of alkali metal alkanoate $\left(\mathrm{M}\left(\mathrm{OOCC}_{n} \mathrm{H}_{2 n+1}\right)\right)$ LC melts was discov ered ${ }^{[13]}$ Related systems with alkaline earth metals could be obtained using organically modified sulfonates. ${ }^{[14]}$ However, cationic or neutral surfactants in combination with metal species also deserve attention. The interaction of the cationic cetyl trimethylammonium SURF with anionic, silicate species has led to the development of ordered mesoporous materials through the synergistic coassembly mechanism. ${ }^{[15]}$ There are now numerous examples of the preparation of various mesoporous metal oxide materials with the aid of surfactants as template phases. ${ }^{[3 a, 16]}$ Another interesting area is the combination of anionic metal species, such as palladates, aluminates, etc., with cationic surfactants and in particular with ionic liquids, ${ }^{[17]}$ that is, molecular systems that are very similar to surfactants with large, cationic heads. Most of the 
latter examples have concentrated on catalytic activity or electrochemical functions rather than self assembly. ${ }^{[18]}$

Some spectacular results which deserve special attention were obtained by using polyoxometalates (POMs) as negative counteranions for cationic ammonium surfactants. ${ }^{[19]}$ POMs consist of multinuclear metal oxide building blocks $\left[\mathrm{MO}_{x}\right]$ and are widely known for their interesting properties in catalysis and magnetism. ${ }^{[20]}$ The best explored class of POMs are heteropolyanions with Keggin $\left(\left[\mathrm{XM}_{12} \mathrm{O}_{40}\right]^{n-}\right)$ or Wells Daw son structures $\left(\left[\mathrm{X}_{2} \mathrm{M}_{18} \mathrm{O}_{62}\right]^{n-}\right.$, with $\mathrm{M}=\mathrm{W}, \mathrm{Mo} ; \mathrm{X}=\mathrm{a}$ central atom in tetrahedral coordination, for example, $\mathrm{P}^{\mathrm{V}}$ ). Even more complex compounds can be obtained with isopolyan ions without a central heteroatom. Müller and co workers, for example, reported in a series of pioneering studies that growth to nanoscaled POM clusters can be achieved by partial reduction, for example, of $\mathrm{Mo}^{\mathrm{VI}}$ to $\mathrm{Mo}^{\mathrm{V}}$ species. ${ }^{[21]}$ As a consequence of the large number, presumably thousands, of polyoxometalates that exist, it is beyond the scope of this Minireview to give an extensive overview of the POM field. ${ }^{[20 a]}$ However, the POM SURF hybrid systems represent excellent examples of surfactant encapsulated clusters (SECs). Kurth et al. created SECs by replacing the counter cations of anionic molybdovanadato POMs by long alkyl chained cationic ammonium surfactants. ${ }^{[19 \mathrm{~b}, 22]}$ A close packing of the alkyl chains was observed, and it was concluded that there is a compact shell around the POM. The surfactant shell improves the stability of the embedded POM as well as its solubility in nonpolar, aprotic organic solvents. Furthermore, the self assembling behavior was studied extensively. The SECs form highly ordered and homogeneous films when deposited by the Langmuir Blodgett $(\mathrm{LB})^{[23]}$ technique. Ordered 2D arrays of the SEC were formed after evaporation of the solvent.

Our research group presented a unique system in 2001, which was later "re discovered" by Cronin and co work ers. ${ }^{[19 e, 24]}$ Giant, donut shaped POMs were treated with a cationic, double tailed surfactant. It was found that the surfactant binds exclusively at the periphery of the inorganic POM cluster (Figure 2). A novel species with special, quad rupolar amphiphilic properties (hydrophilic, hard, inorganic core and hydrophobic, soft, organic shell) was formed by self organization into columnar LLC phases. Furthermore, it was shown that the presence of the inorganic building block afforded the system additional, catalytic properties.

An important extension of the SEC approach was realized when encapsulation of the surfactant was combined with covalent modification of the POM cluster. These novel systems are known as surfactant encapsulated organically grafted polyoxometalates (SEOPs), as pioneered by $\mathrm{Wu}$ and co workers. ${ }^{[25]}$ The authors equipped the Mn Anderson POM with stimuli responsive building blocks such as azobenzene groups to gain smart self assembled structures (Figure 3). The self assembly behavior is controlled by photoirradiation, which destroys and rebuilds the hydrogen bonds. Upon

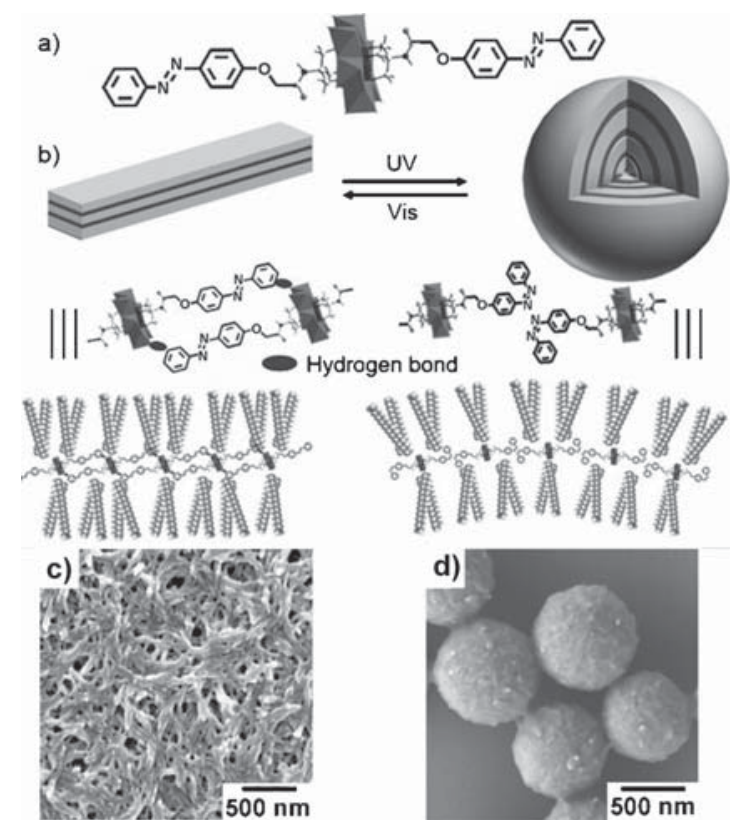

Figure 3. a) Structure of the azobenzene modified Mn Anderson POM cluster. b) Schematic representation of the light stimulated self organ ization behavior. SEM images before (c) and after radiation (d). Reproduced from Ref. [25] with permission. Copyright 2010, Wiley $\mathrm{VCH}$.

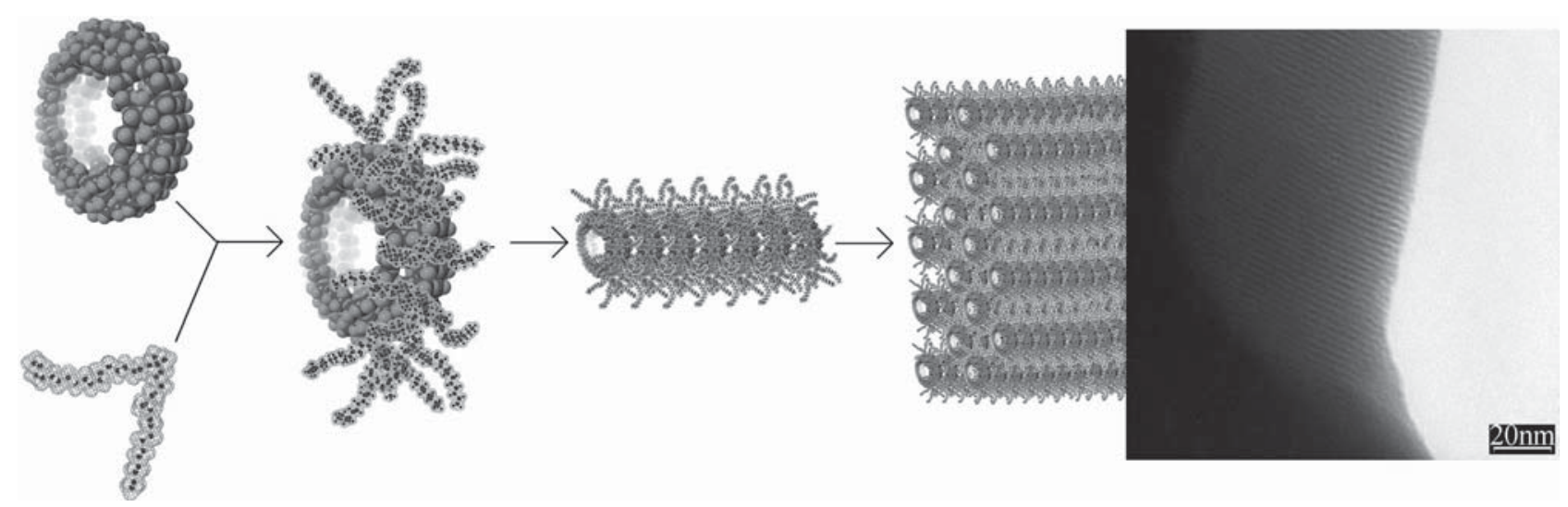

Figure 2. Self assembly of a giant, disklike POM containing 176 Mo atoms through electrostatic binding of dioctadecyldimethylammonium as a cationic surfactant; mechanism and TEM micrograph. Reproduced from Ref. [19e] with permission. Copyright 2001, Wiley VCH. 
irradiation with UV light (365 nm) the fiberlike morphology of the SEOP (with azobenzene groups in the trans conforma tion) transforms reversibly into spherical aggregates. The described smart behavior can be expanded by changing the covalently bonded organic moiety of the SEOP. Accordingly, a SEOP with thermoresponsive properties was reported for a POM modified with adenine units, ${ }^{[26]}$ and an SEOP with electrochemical stimuli was reported when ferrocene units were used for covalent anchoring. ${ }^{[27]}$ In a similar way, some recent reports describe the formation of interesting structures by the reaction of surfactants with metal containing poly electrolyte species with coordination polymers. ${ }^{[28]}$

\section{Metal Species as Integral Constituents of the I-SURF Head Group}

\subsection{I-SURFs with Organic Ligands (Type Ila)}

The generation of surfactants with a head group contain ing one single metal center is straightforward at first glance. The basic idea is that a charged metal complex fragment coordinates to a chelating organic ligand which is modified by one long, hydrophobic chain (Scheme 2). At second glance it

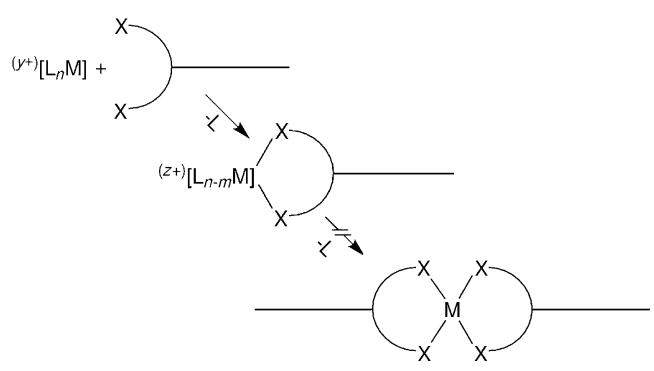

Scheme 2. Typical synthesis route for I SURFs containing an organic ligand modified by a long paraffinic chain. ( $L$ ligand; $M$ metal center; $X$ donor center.)

becomes apparent that the latter approach is quite demand ing. Difficulties arise because it is actually not so easy to prepare asymmetric molecular species. The preparation of the required organic ligands can be quite tedious, and it might be difficult to attach only one hydrocarbon chain. Furthermore, the successive reaction of the metal center with a second ligand is generally not preferred, because it leads to com pounds with less dipolar and enhanced hydrophobic character (Scheme 2). Exceptions occur if the coordination geometry of the metal atom can facilitate the orientation of all the hydrophobic chains into one direction. ${ }^{[2]}$ Consequently, it is favorable if the metal center prefers low coordination numbers or the ligand contains a rather high number of chelating donor centers.

Examples which are still closely related to I SURFs/type I were reported by Bruce et al. ${ }^{[30]}$ For example, the authors claim that the exchange of a labile ligand of an octahedral complex for a long chain amine leads to a surfactant species. Unfortunately, the $\mathrm{M}-\mathrm{N}$ bond was cleaved rapidly in water. a)
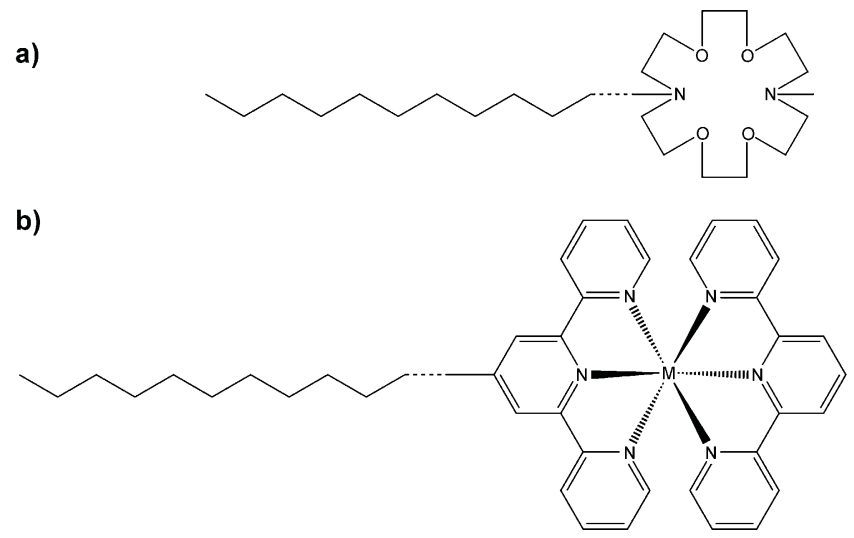

Figure 4. Two different chelating ligands used for the I SURF design type Ila. a) Crown ether inspired head group (prior to metal coordina tion). ${ }^{[3]}$ b) I SURF with a bipyridine type head group. ${ }^{[33]}$

More complex ligands were used by Le Moigne and Simon, who were able to combine the metal binding properties of crown ethers with surfactant design (Figure $4 \mathrm{a}$ ). ${ }^{[31]}$ A similar surfactant system and its self organization behavior was presented by Neve et al. ${ }^{[32]}$ This study is noteworthy because the authors succeeded in characterizing their $\mathrm{Ag}^{+}$containing surfactant through single crystal $\mathrm{X}$ ray analysis (Figure 5), which is very rare for SURF systems.

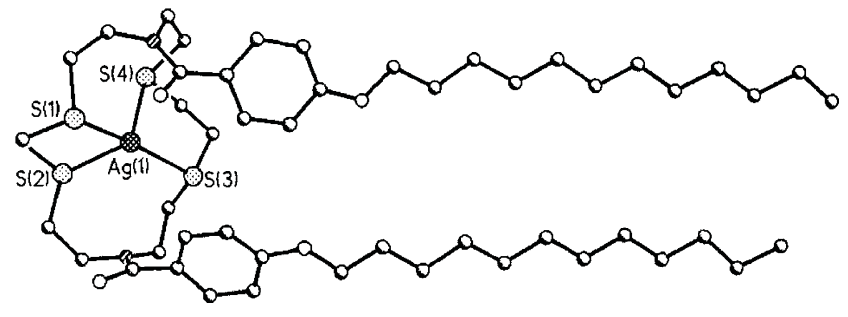

Figure 5. Crystal structure of an $\mathrm{Ag}^{+}$containing I SURF of type Ila. Reproduced from Ref. [29] with permission. Copyright 1996, Wiley $\mathrm{VCH}$.

Later Bruce and co workers introduced the concept of using bipyridine derivatives and related compounds as ligands for the synthesis of I SURFs of type IIa. ${ }^{[33,34]}$ An impressive case involves the bis(terpyridine) complexes shown in Fig ure $4 \mathrm{~b}{ }^{[33]}$ A double tailed surfactant with the vanadyl cation as a magnetic transition metal center was presented by Zhu and Swager ${ }^{[35]}$ Binnemans and Görller Walrand studied the preparation of surfactants containing lanthanides. They presented tailor made ligands characterized by seven donor centers encapsulating the metal ion. ${ }^{[12 \mathrm{~b}, 36]}$

Most of the publications concentrated on the synthesis of the surfactant molecules and the study of their self organ ization (thermotropic and lyotropic). However, one of the first examples addressing the advanced set of properties of I SURFs was presented in a stimulating study by Matyjas zewski et al. ${ }^{[37]}$ The authors have prepared different tridentate nitrogen based ligands which were modified by a long alkyl chain. After coordination of $\mathrm{Cu}^{\mathrm{I}}$, it was possible to use the I SURF for atom transfer radical polymerization (ATRP). 


\subsection{I-SURFS with Inorganic Entities as Head Groups (Type IIb)}

Examples of surfactants with pure inorganic head groups (Scheme 2; type IIb) are much rarer, with the first only being published very recently. The attachment of multinuclear transition metal entities as head groups to an organic alkyl chain is very difficult because many $\mathrm{M}-\mathrm{X}$ linkages $(\mathrm{X}=\mathrm{C}, \mathrm{O}$, $\mathrm{N}$ ) are susceptible to hydrolysis. Clearly, cleavage of the alkyl chain in water would destroy any amphiphilic properties. However, recent studies in the field of polyoxometalate chemistry (POM) has resulted in some highly innovative surfactant species that are stable in water, and some interest ing studies about their self assembly have been published. ${ }^{[38]}$

An early amphiphilic POM system starting from a tris alkoxy modified Mn Anderson POM was presented by Cronin, Liu, and co workers. ${ }^{[39]}$ An alkyl chain was attached to both sites of the $\left[\mathrm{MnMo}_{6} \mathrm{O}_{24}\right]$ cluster through amide bonds. It was shown that the amphiphilic system self assembles into large vesicular structures (Figure 6). This was the first

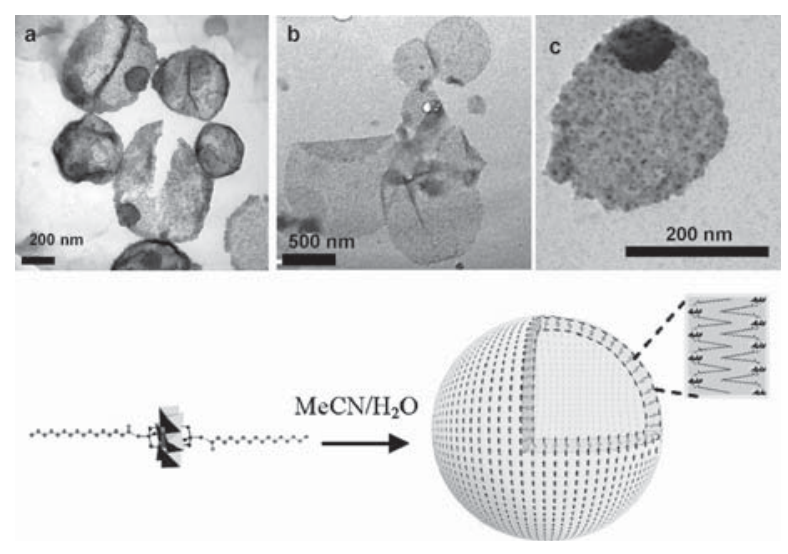

Figure 6. Formation of vesicles by the Mn Anderson POM I SURF in an acetonitrile/water mixture; TEM micrographs and formation mech anism. Reprinted from Ref. [39] with permission. Copyright 2008, American Chemical Society.

example of POM amphiphiles that arrange into vesicles. However, the system has two disadvantages. The amphiphile is insoluble in water due to the presence of the bulky TBA ions. Self assembly could only occur when significant amounts of acetonitrile were added. Furthermore, the geometry of the amphiphile is unfavorable with respect to the ideal dipolar character of a surfactant, because the hydrophobic tails are symmetrically attached on each site of the head group. As a consequence, the tails have to bend significantly to form a vesicular structure. This makes vesicle formation more difficult and the self assembly process takes more time (57 days to reach equilibrium) compared to classical surfac tants. Nevertheless, an amphiphile with this geometry is more appropriate for the self assembly of reverse aggregates in apolar solvents. ${ }^{[40]}$ Reverse vesicles with relatively low polydispersity were also found. The length of the alkyl tail has a minor effect on the self assembly process, but the solvent polarity changes the vesicle size.
Another remarkable POM surfactant was presented by the research group of Wang in 2010. A $\mathrm{V}_{3}$ capped Dawson POM was equipped with an ATRP initiator building block, which was used to initiate the polymerization of styrene. ${ }^{[41]}$ Afterwards, the TBA ions were exchanged with protons. The DMF solution became opaque, thus indicating the arising amphiphilic character of the POM PS compound. The POM PS amphiphile self assembles into reverse vesicular aggre gates with a mean diameter of $166 \mathrm{~nm}$. The aggregates consist of a bright shell, a dark core, and a dark, thin ring between the core and shell. The vesicles exhibit a bilayer membrane, with the POM clusters located in the middle of the membrane. The calculated thickness of the membrane is $64 \mathrm{~nm}$, which is a huge value for bilayer membranes. ${ }^{[42]}$

The attention of our research group was devoted to the use of POMs as an integral part of a surfactant. A lacunary tungstate of the Keggin type $\left[\mathrm{PW}_{11} \mathrm{O}_{39}\right]^{7-}$ was modified by the attachment of two long alkyl chains (Figure 7). ${ }^{[43]}$ This system fulfills all the key criteria for an amphiphile. It can be used to

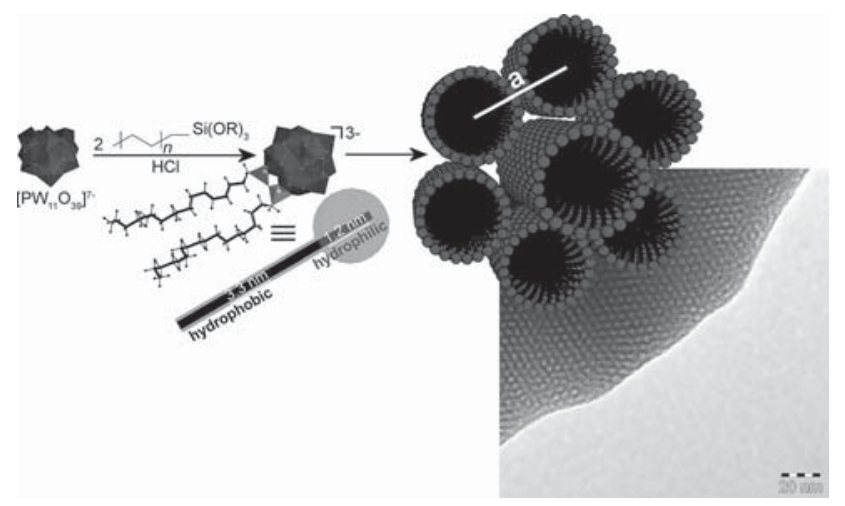

Figure 7. Synthesis and LLC formation of an anionic I SURF with a $\left[\mathrm{PW}_{11} \mathrm{O}_{39}\right]^{3-}$ head group. Reprinted from Ref. [43] with permission. Copyright 2010, American Chemical Society.

form micelles, liquid crystals, and even very stable emulsions. However, it was discovered that the novel surfactant system shows several unique features that go beyond the properties of conventional, organic surfactants (Figure 1). First, there is a huge difference in the electronic density between the head group with $11 \mathrm{~W}$ atoms and the side chain $\left(\mathrm{CH}_{2}\right)_{n}(n=1220)$. This leads to a natural contrast for numerous analytical methods such as TEM and also for scattering techniques. The self assembled structures can be observed very easily and very precisely. For example, the formation of LB monolayers at the air/water interface was followed by using grazing incidence $X$ ray diffraction. ${ }^{[44]}$ The observed supramolecular $2 \mathrm{D}$ structured ordering at the air/water interface was the first example arising from packing of the hydrophilic head groups rather than the hydrophobic tails. Consequently, the $\left[\mathrm{PW}_{11} \mathrm{O}_{39}\right]$ compounds represent valuable model systems in surfactant science. ${ }^{[4]}$ Additional functionalities could also be demonstrated. For example, we showed that the $\left[\mathrm{PW}_{11} \mathrm{O}_{39}\right]$ surfactant with $\mathrm{H}^{+}$as the counterion is able to fulfill two functions at once. It is an emulsification agent and at the same time a polymerization catalyst. ${ }^{[43,45]}$ It is apparent that the 
remaining parts of POM surfactants can also be subjected to modifications. These parts include the counterion to the negatively charged head, the hydrophobic chain(s), and the head group itself. We showed in a recent publication that the modification of the organic chain also only leads to the emergence of unexpected and unprecedented surfactant properties. ${ }^{[46]}$ A bipolar, bolaform surfactant (Figure 8a)

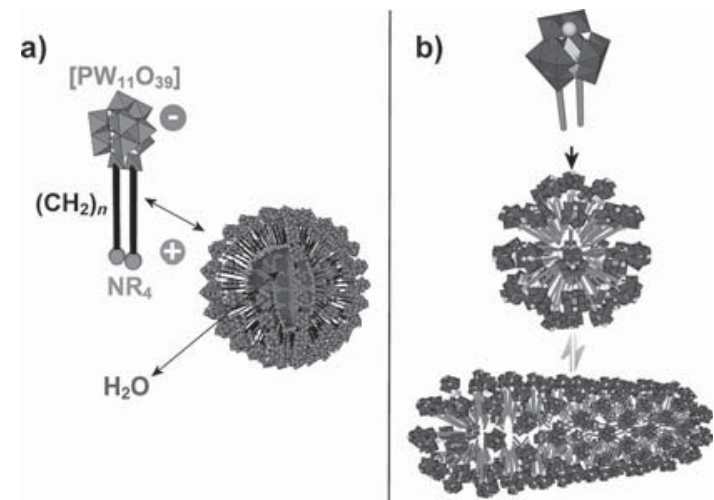

Figure 8. a) A bipolar $\left[\mathrm{PW}_{11} \mathrm{O}_{39}\right]$ surfactant and its self organization into ultrasmall monolayer vesicles. Reprinted from Ref. [46] with permission. Copyright (2012) Nature Publishing. b) Formation of micelles from bimetallic POM I SURFs and the reversible electrochem ical switching from spherical to rodlike micelles. Reprinted from Ref. [48] with permission. Copyright 2012, Wiley VCH.

was prepared. This surfactant leads to the formation of one of the smallest monolayer membrane (MLM) vesicles in water known to date (diameter $15 \mathrm{~nm}$ ), which is associated with an extremely low critical aggregation concentration (CAC) of only $3 \times 10^{-6} \mathrm{~mol} \mathrm{~L}^{-1}$. This CAC even lies below the range of nonionic, polymeric detergents. ${ }^{[4]}$ We have since undertaken the first steps towards further exploring the $\left[\mathrm{PW}_{11} \mathrm{O}_{39}\right]$ surfactant system. The chemical complexity of the head group can be enhanced even more by the introduction of a second transition metal. ${ }^{[48]}$ We showed that the synthesis of a bimetallic head group with ruthenium as the second metal is feasible. In addition to the typical surfactant properties, such as the ability to form liquid crystals, micelles, etc., we reported that the presence of this special inorganic head group enables several unique features. Unlike any known surfactant, the charge of the head group can be adjusted reversibly within the range $(-1) \rightleftarrows(-2) \rightleftarrows(-3) \rightleftarrows(-4)$. This is due to the redox activity and the associated redox systems of $\mathrm{Ru}^{\mathrm{II}} / \mathrm{Ru}^{\mathrm{III}} / \mathrm{Ru}^{\mathrm{IV}}$ and $\mathrm{W}^{\mathrm{V}} / \mathrm{W}^{\mathrm{VI}}$. For the first time it was possible to investigate how a systematic variation of the head group charge would affect self assembly behavior. We showed by using a combi nation of analytical techniques such as small angle $\mathrm{X}$ ray scattering (SAXS) and analytical ultracentrifugation that there is a transition from conventional spherical to rodlike micelles on reduction (Figure $8 \mathrm{~b}$ ). An additional conse quence of the described redox chemistry is that the surfactant can be switched from diamagnetic $\left(\mathrm{Ru}^{\mathrm{II}}\right)$ to paramagnetic $\left(\mathrm{Ru} \mathrm{u}^{\mathrm{III}}\right)$, as evident from electron paramagnetic resonance (EPR) spectroscopy studies. ${ }^{[48]}$

Later, Liu, Wei, and co workers presented a system with two octadecyl chains grafted through ester bonds onto opposite sites of a pentaerythritol modified hexavanadate ion with a Lindqvist structure. ${ }^{[4]}$ It is remarkable that this amphiphile showed different fluorescence properties when the counterion of the POM was exchanged from TBA to $\mathrm{H}^{+}$ or $\mathrm{Na}^{+}$. The origin of the emission probably involves an emissive state derived from a ligand to metal charge trans fer. ${ }^{[50]}$ Moreover, the self assembly of the amphiphile in water induced an increase in the the fluorescence intensity. The enhanced stability against photobleaching enabled the self organized structure to be investigated by fluorescence microscopy. Furthermore, this system can act as a highly efficient emulsion catalyst for the oxidation of thiophene in the presence of hydrogen peroxide. ${ }^{[51]}$ It is also possible to modify the hexavanadate ion with alternative, more func tional organic groups. Hill and co workers reported the introduction of pyrene units through amide bonds. ${ }^{[52]}$ The amphiphiles self assemble into vesicular structures. It was shown that the kind of counterion influenced the supra molecular packing of the vesicles: The more hydrophobic the counterion, the closer the packing of the vesicles. Conse quently, the fluorescence spectrum of the I SURFs became dominated by emission from the pyrene excimer.

Cronin and co workers have developed another interest ing POM I SURF system with bolaform character. ${ }^{[53]}$ Two $V_{3}$ capped Dawson POMs were linked together through various organic linkers. The resulting dumbbell like compounds show a unique self assembly into MLM vesicles in water/acetone mixtures. This is unusual for bolaform surfactants possessing such a low organic content. Usually, such short organic linkers cannot fill the entire hydrophobic area between the two hydrophilic heads. The Liu research group has extended the number of described dumbbell like systems, and has studied their self assembly behavior in more detail. ${ }^{[54]}$ The authors were able to increase the size of a bolaform surfactant based on a Dawson POM to $4.7 \mathrm{~nm}$ by using a bipyridine linker. Furthermore, the self assembly behavior at the water/air interface was investigated. All the described bolaform amphiphiles form LB monolayers, but the ordering of the monolayer strongly depends on the hydrophobicity of the linker. The most stable LB monolayer was prepared from the POM with a bipyridine linker, and it was concluded that there are additional, attractive $\pi \pi$ interactions between the bipyridine units, which stabilize the structures. ${ }^{[5]}$

All of the above mentioned precursor systems contain hydrophilic heads in combination with alkyl tails as the hydrophobic entity. We thus came up with the idea of preparing a reverse I SURF with an organometallic oxo cluster as the head group. We succeeded in the preparation of a compound containing an alkyl alkoxy zinc cluster attached to two polyethyleneglycol units as a polar chain (Figure 9). ${ }^{[56]}$ Interestingly, this new organometallic amphiphile self assem bles over several length scales. First, the dimers form a lamellar phase through a microphase separation of the hydrophobic oxo cluster entities and the polar PEG domains, as indicated by polarization microscopy, SAXS, and TEM. ${ }^{[56]}$ Swelling of the hydrophobic domains and further structuring occurs when in contact with apolar solvents, such as toluene. Surprisingly, relatively similar sized spheres are formed, and these spheres agglomerate into a close packing, which 


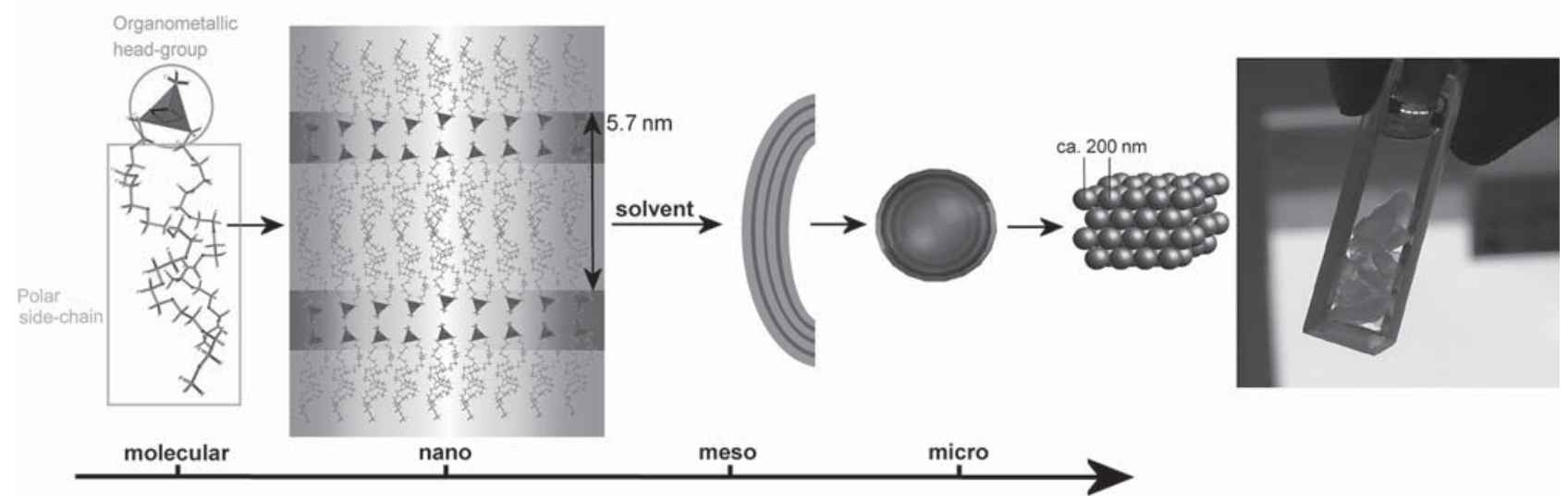

Figure 9. Structure of the first inverse, organometallic I SURF and its self organization over several length scales. Right: Photograph of the final material. Reprinted from Ref. [56] with permission. Copyright 2007, Wiley VCH.

because of the dimension of the single spheres $(200 \mathrm{~nm}$ in size) behaves like an optical grating diffracting light in the visible. This leads to the emergence of blue color (Figure 9), although the system does not contain any chromophore. In comparison to traditional amphiphiles, the discussed system is also different because it contains, as a second function, the ability to act as a precursor for $\mathrm{ZnO}{ }^{[56]}$ Indeed, a bimodal, macro and nanoporous $\mathrm{ZnO}$ could be generated directly from the nanostructured gel while the morphology of the $\mathrm{ZnO}$ was influenced directly by the morphology of the $[\mathrm{MeZnOPEG}]_{2}$ phase.

\section{Conclusions}

This Minireview has discussed different strategies of how surfactants containing metal entities as head groups can be obtained, and some of the most impressive examples from the literature were highlighted. It was shown that it is quite straightforward to extend the set of classical properties of surfactants (Figure 1). However, the synthesis of the desired I SURFs can be demanding, and currently only a few examples exist. One particular problem is the necessity to prepare asymmetric molecules, preferentially with distinct dipolar character.

However, the most important feature of I SURFs is their potential in terms of the emergence of synergistic properties. Synergy implies that a system of two (or more) constituents gains qualities that none of the single components has by itself. Furthermore, the new properties are more than a pure, linear combination, which makes them very difficult to predict or even to plan. Accordingly, the number of examples of synergy in (materials) chemistry is still quite small. ${ }^{[57]}$ In this respect, it is remarkable that most of the I SURFs presented in this Minireview show some totally unexpected and unprecedented properties that can be interpreted as the result of a synergistic relationship. Most of the cases considered here involve the emergence of unique structures formed by self assembly. This outstanding characteristic of I SURF systems might be attributed to additional or at least modified modes of interaction between the surfactant mole cules. Although interactions such as dispersion forces, hydro gen bonding, dipolar interactions, and the hydrophobic effect have to be considered for ordinary mesophases, there are potentially additional factors, for example, magnetic inter actions, for I SURFs. Furthermore, the large extension of the head and a potentially asymmetric charge density distribution could also influence the mutual packing of those hybrid surfactants and can not be excluded.

The field of inorganic surfactants is still in its infancy. The aim of future research will be to provide a larger variety of I SURFs and to understand what makes their properties concerning self organization so unique. Furthermore, the exploration of their potential concerning concrete applica tions such as in catalysis, drug delivery, smart materials, and beyond will open new vistas in materials research.

Received: April 15, 2013

Published online: November 15, 2013

[1] R. Nagarajan, E. Ruckenstein, Langmuir 1991, 7, 29342969.

[2] H. Stache, K. Kosswig, Surfactant Pocketbook., 3rd ed., Hanser, Munich, 1990.

[3] a) S. Polarz, B. Smarsly, J. Nanosci. Nanotechnol. 2002, 2, 581 612; b) H. Weller, Curr. Opin. Colloid Interface Sci. 1998, 3, 194 199 ; c) S. Förster, T. Plantenberg, Angew. Chem. 2002, 114, 712 739; Angew. Chem. Int. Ed. 2002, 41, 688714.

[4] J. N. Israelachvili, Intermolecular and Surface Forces, Elsevier, Oxford, 2011.

[5] a) A. M. Giroud Godquin, P. M. Maitlis, Angew. Chem. 1991, 103, 370 398; Angew. Chem. Int. Ed. Engl. 1991, 30, 375 402; b) S. A. Hudson, P. M. Maitlis, Chem. Rev. 1993, 93, 861885. [6] P. M. Maitlis, D. W. Bruce, R. Dhillon, D. A. Dunmur, F. P. Fanizzi, S. E. Hunt, R. Lelagadec, E. Lalinde, R. Orr, J. P. Rourke, N. J. S. Salt, J. P. Stacey, P. Styring, New J. Chem. 1990, $14,549551$.

[7] a) T. C. Bedard, J. S. Moore, J. Am. Chem. Soc. 1995, 117, 10662 10671; b) D. W. Bruce, Acc. Chem. Res. 2000, 33, 831840.

[8] a) L. Oriol, J. L. Serrano, Adv. Mater. 1995, 7, 348 369; b) X. H. Liu, D. W. Bruce, I. Manners, Chem. Commun. 1997, 289 290; c) G. R. Whittell, I. Manners, Adv. Mater. 2007, 19, 3439 3468; d) A. S. Sonin, J. Mater. Chem. 1998, 8, 2557 2574; e) A. L. 
Rogach, D. V. Talapin, E. V. Shevchenko, A. Kornowski, M Haase, H. Weller, Adv. Funct. Mater. 2002, 12, 653 664;f) G. A Ozin, Chem. Commun. 2000, 419 432; g) S. Polarz, Adv. Funct. Mater. 2011, 21, 32143230.

[9] a) J. M. Lehn, Angew. Chem. 1988, 100, 91 116; Angew. Chem. Int. Ed. Engl. 1988, 27, 89 112; b) C. Janiak, Dalton Trans. 2003 2781 2804; c) S. Kitagawa, R. Kitaura, S. Noro, Angew. Chem. 2004, 116, 2388 2430; Angew. Chem. Int. Ed. 2004, 43, 2334 2375.

[10] P. G. Pickup, J. Mater. Chem. 1999, 9, 16411653.

[11] a) E. C. Constable, Chem. Commun. 1997, 1073 1080; b) G. R. Newkome, E. F. He, C. N. Moorefield, Chem. Rev. 1999, 99, 16891746.

[12] a) K. Binnemans, Chem. Rev. 2005, 105, 4148 4204; b) B. Donnio, Curr. Opin. Colloid Interface Sci. 2002, 7, 371394.

[13] T. A. Mirnaya, V. D. Prisyazhnyi, V. A. Shcherbakov, Usp. Khim. 1989, 58, 14291450.

[14] a) D. Tezak, F. Strajnar, O. Milat, M. Stubicar, Prog. Colloid Interface Sci. 1984, 69, 100 105; b) D. Tezak, O. Babacic, V. Derek, M. Galesic, S. Heimer, V. Hrust, Z. Ivezic, D. Jurkovic, S. Rupcic, V. Zelovic, Colloid Surf. A 1994, 90, 261 270; c) D. Tezak, M. Martinis, S. Puncec, I. Fischerpalkovic, F. Strajnar, Liq. Cryst. 1995, 19, 159167.

[15] a) Q. S. Huo, D. I. Margolese, U. Ciesla, P. Y. Feng, T. E. Gier, P. Sieger, R. Leon, P. M. Petroff, F. Schüth, G. D. Stucky, Nature 1994, 368, 317 321; b) A. Monnier, F. Schüth, Q. Huo, D. Kumar, D. Margolese, R. S. Maxwell, G. D. Stucky, M. Krishna murty, P. Petroff, A. Firouzi, M. Janicke, B. F. Chmelka, Science 1993, 261, 12991303

[16] a) G. J. D. Soler illia, C. Sanchez, B. Lebeau, J. Patarin, Chem. Rev. 2002, 102, 4093 4138; b) P. D. Yang, D. Y. Zhao, D. I. Margolese, B. F. Chmelka, G. D. Stucky, Nature 1998, 396, 152 155.

[17] a) T. Welton, Chem. Rev. 1999, 99, 2071 2083; b) J. Dupont, R. F. de Souza, P. A. Z. Suarez, Chem. Rev. 2002, 102, 3667 3691.

[18] a) P. Wasserscheid, W. Keim, Angew. Chem. 2000, 112, 3926 3945; Angew. Chem. Int. Ed. 2000, 39, 3772 3789; b) T. Welton, Coord. Chem. Rev. 2004, 248, 2459 2477; c) M. Armand, F. Endres, D. R. MacFarlane, H. Ohno, B. Scrosati, Nat. Mater 2009, 8, 621629.

[19] a) E. Coronado, C. J. Gomez Garcia, Chem. Rev. 1998, 98, 273 296; b) D. G. Kurth, P. Lehmann, D. Volkmer, H. Cölfen, M. J. Koop, A. Müller, A. Du Chesne, Chem. Eur. J. 2000, 6, 385 393; c) H. Li, H. Sun, W. Qi, M. Xu, L. Wu, Angew. Chem. 2007, 119, 1322 1325; Angew. Chem. Int. Ed. 2007, 46, 1300 1303; d) A. Nisar, X. Wang, Dalton Trans. 2012, 41, 9832 9845; e) S. Polarz, B. Smarsly, M. Antonietti, ChemPhysChem 2001, 2, 457 461; f) W. Bu, S. Uchida, N. Mizuno, Angew. Chem. 2009, 121, 8431 8434; Angew. Chem. Int. Ed. 2009, 48, 82818284.

[20] a) D. L. Long, E. Burkholder, L. Cronin, Chem. Soc. Rev. 2007, 36, 105 121; b) A. Proust, R. Thouvenot, P. Gouzerh, Chem. Commun. 2008, 18371852.

[21] a) U. Kortz, A. Müller, J. van Slageren, J. Schnack, N. S. Dalal, M. Dressel, Coord. Chem. Rev. 2009, 253, 2315 2327; b) A. Müller, E. Beckmann, H. Bogge, M. Schmidtmann, A. Dress, Angew. Chem. 2002, 114, 1210 1215; Angew. Chem. Int. Ed. 2002, 41, 11621167.

[22] F. Caruso, D. G. Kurth, D. Volkmer, M. J. Koop, A. Müller, Langmuir 1998, 14, 34623465.

[23] A. Ulman, Chem. Rev. 1996, 96, 15331554.

[24] S. i. Noro, R. Tsunashima, Y. Kamiya, K. Uemura, H. Kita, L. Cronin, T. Akutagawa, T. Nakamura, Angew. Chem. 2009, 121 , 8859 8862; Angew. Chem. Int. Ed. 2009, 48, 87038706.

[25] Y. Yan, H. Wang, B. Li, G. Hou, Z. Yin, L. Wu, V. W. Yam, Angew. Chem. 2010, 122, 9419 9422; Angew. Chem. Int. Ed. 2010, 49, 92339236.
[26] Z. He, Y. Yan, B. Li, H. Ai, H. Wang, H. Li, L. Wu, Dalton Trans. 2012, 41, 1004310051.

[27] Y. Yan, B. Li, Q. He, Z. He, H. Ai, H. Wang, Z. Yin, L. Wu, Soft Matter 2012, 8, 1593.

[28] a) G. Schwarz, Y. Bodenthin, Z. Tomkowicz, W. Haase, T. Geue, J. Kohlbrecher, U. Pietsch, D. G. Kurth, J. Am. Chem. Soc. 2011, 133, 547558 ; b) S. C. Junggeburth, L. Diehl, S. Werner, V. Duppel, W. Sigle, B. V. Lotsch, J. Am. Chem. Soc. 2013, 135, 61576164.

[29] F. Neve, Adv. Mater. 1996, 8, 277289.

[30] a) D. W. Bruce, D. A. Dunmur, P. M. Maitlis, J. M. Watkins, G. J. T. Tiddy, Liq. Cryst. 1992, 11, 127 133; b) D. W. Bruce, I. R. Denby, G. J. T. Tiddy, J. M. Watkins, J. Mater. Chem. 1993, 3, 911916.

[31] J. Le Moigne, J. Simon, J. Phys. Chem. 1980, 84, 170177.

[32] F. Neve, M. Ghedini, G. Demunno, A. M. Levelut, Chem. Mater. 1995, 7, 688693.

[33] J. D. Holbrey, G. J. T. Tiddy, D. W. Bruce, Dalton Trans. 1995, 17691774.

[34] D. W. Bruce, J. D. Holbrey, A. R. Tajbakhsh, G. J. T. Tiddy, J. Mater. Chem. 1993, 3, 905906.

[35] S. S. Zhu, T. M. Swager, Adv. Mater. 1995, 7, 280283.

[36] K. Binnemans, C. Gorller Walrand, Chem. Rev. 2002, 102, 2303 2345.

[37] K. Matyjaszewski, B. Göbelt, H. j. Paik, C. P. Horwitz, Macro molecules 2001, 34, 430440.

[38] a) M. H. Rosnes, C. Musumeci, C. P. Pradeep, J. S. Mathieson, D. L. Long, Y. F. Song, B. Pignataro, R. Cogdell, L. Cronin, J. Am. Chem. Soc. 2010, 132, 15490 15492; b) D. L. Long, R. Tsunashima, L. Cronin, Angew. Chem. 2010, 122, 1780 1803; Angew. Chem. Int. Ed. 2010, 49, 1736 1758; c) A. Dolbecq, E. Dumas, C. R. Mayer, P. Mialane, Chem. Rev. 2010, 110, 6009 6048; d) A. Proust, B. Matt, R. Villanneau, G. Guillemot, P. Gouzerh, G. Izzet, Chem. Soc. Rev. 2012, 41, 7605 7622; e) C. Sanchez, G. J. A. A. Soler Illia, F. Ribot, T. Lalot, C. R. Mayer, V. Cabuil, Chem. Mater. 2001, 13, 3061 3083; f) P. Yin, L. Jin, D. Li, P. Cheng, D. V. Vezenov, E. Bitterlich, X. Wu, Z. Peng, T. Liu, Chemistry 2012, 18, 6754 6758; g) Y. F. Song, R. Tsunashima, Chem. Soc. Rev. 2012, 41, 7384 7402; h) P. Yin, D. Li, T. Liu, Chem. Soc. Rev. 2012, 41, 73687383.

[39] J. Zhang, Y. F. Song, L. Cronin, T. Liu, J. Am. Chem. Soc. 2008, 130, 1440814409.

[40] J. Zhang, Y. F. Song, L. Cronin, T. Liu, Chemistry 2010, 16, 1132011324

[41] Y. Han, Y. Xiao, Z. Zhang, B. Liu, P. Zheng, S. He, W. Wang, Macromolecules 2009, 42, 65436548.

[42] Y. Xiao, Y. K. Han, N. Xia, M. B. Hu, P. Zheng, W. Wang, Chemistry 2012, 18, 1132511333.

[43] S. Landsmann, C. Lizandara Pueyo, S. Polarz, J. Am. Chem. Soc. 2010, 132, 53155321.

[44] J. J. Giner Casares, G. Brezesinski, H. Mohwald, S. Landsmann, S. Polarz, J. Phys. Chem. Lett. 2012, 3, 322326.

[45] S. Polarz, S. Landsmann, Z. Anorg. Allg. Chem. 2010, 636, 2038.

[46] S. Landsmann, M. Luka, S. Polarz, Nat. Commun. 2012, 3, 1299.

[47] D. Schwarz, F. Junge, F. Durst, N. Frölich, B. Schneider, S. Reckel, S. Sobhanifar, V. Dötsch, F. Bernhard, Nat. Protoc. 2007, 2, 29452957.

[48] S. Landsmann, M. Wessig, M. Schmid, H. Colfen, S. Polarz, Angew. Chem. 2012, 124, 6097 6101; Angew. Chem. Int. Ed. 2012, 51, 59955999.

[49] P. Yin, P. Wu, Z. Xiao, D. Li, E. Bitterlich, J. Zhang, P. Cheng, D. V. Vezenov, T. Liu, Y. Wei, Angew. Chem. 2011, 123, 2569 2573; Angew. Chem. Int. Ed. 2011, 50, 25212525.

[50] L. Chen, F. Jiang, Z. Lin, Y. Zhou, C. Yue, M. Hong, J. Am. Chem. Soc. 2005, 127, 85888589.

[51] P. Yin, J. Wang, Z. Xiao, P. Wu, Y. Wei, T. Liu, Chem. Eur. J. 2012, 18, 91749178. 
[52] D. Li, J. Song, P. Yin, S. Simotwo, A. J. Bassler, Y. Aung, J. E. Roberts, K. I. Hardcastle, C. L. Hill, T. Liu, J. Am. Chem. Soc. 2011, 133, 1401014016.

[53] C. P. Pradeep, M. F. Misdrahi, F. Y. Li, J. Zhang, L. Xu, D. L. Long, T. Liu, L. Cronin, Angew. Chem. 2009, 121, 8459 8463; Angew. Chem. Int. Ed. 2009, 48, 83098313.

[54] M. F. Misdrahi, M. Wang, C. P. Pradeep, F. Y. Li, C. Lydon, L. Xu, L. Cronin, T. Liu, Langmuir 2011, 27, 91939202.
[55] V. M. Kaganer, H. Möhwald, P. Dutta, Rev. Mod. Phys. 1999, 71, 779819.

[56] S. Polarz, R. Regenspurger, J. Hartmann, Angew. Chem. 2007, 119, 2478 2482; Angew. Chem. Int. Ed. 2007, 46, 24262430.

[57] a) J. J. Becker, M. R. Gagne, Acc. Chem. Res. 2004, 37, 798 804; b) P. Gomez Romero, Adv. Mater. 2001, 13, 163174 